\title{
A benign colorectal lesion with amorphous pit (Kudo Vn) and avascular pattern (Sano's 3b): differential diagnosis with deep invasive adenocarcinoma
}

Endoscopic analysis with virtual chromoendoscopy, including narrow-band imaging (NBI), allows the prediction of histology and invasion depth for neoplastic lesions in the colon.

The first case we present here is that of a 60 -year-old woman referred for colonoscopy with abdominal pain and rectal bleeding. Her colon was diverticular and we detected an irregular brownish polypoid lesion within the sigmoid. The polypoid component presented an amorphous pit pattern (Kudo's Vn) without a clear demarcation line [1]. The vascular pattern was patchy with avascular areas and large thick vessels corresponding to Sano's type 3b [2] ( Fig. 1; Video 1). According to the NICE classification, we diagnosed a type III lesion [3] suggestive of deep submucosal adenocarcinoma in a laterally spreading tumor [4].

Nevertheless, the polypoid lesion was small and reddish and it was unlikely that this lesion was malignant. Precise assessment of the lesion allowed the detection of a diverticular hole close to the lesion and we discussed the possibility of an inflammatory reaction following diverticulitis. Histology later confirmed this second benign option.

A second similar case was that of a 63-year-old man referred for global endoscopic check-up after an esophageal tumor had recently been diagnosed in our unit. He also had a sigmoid lesion with pseudo-depressed appearance, amorphous mucosal pattern, and irregular vascular pattern ( Fig. 2 ; $\triangleright$ Video 1 ), but histology was benign. This lesion was located by a diverticular orifice, close to an inflammatory process in the wall of the diverticulum.

Inflammatory lesions can therefore present endoscopic malignant features when considering the pit and vascular pattern. The history of diverticulitis, the
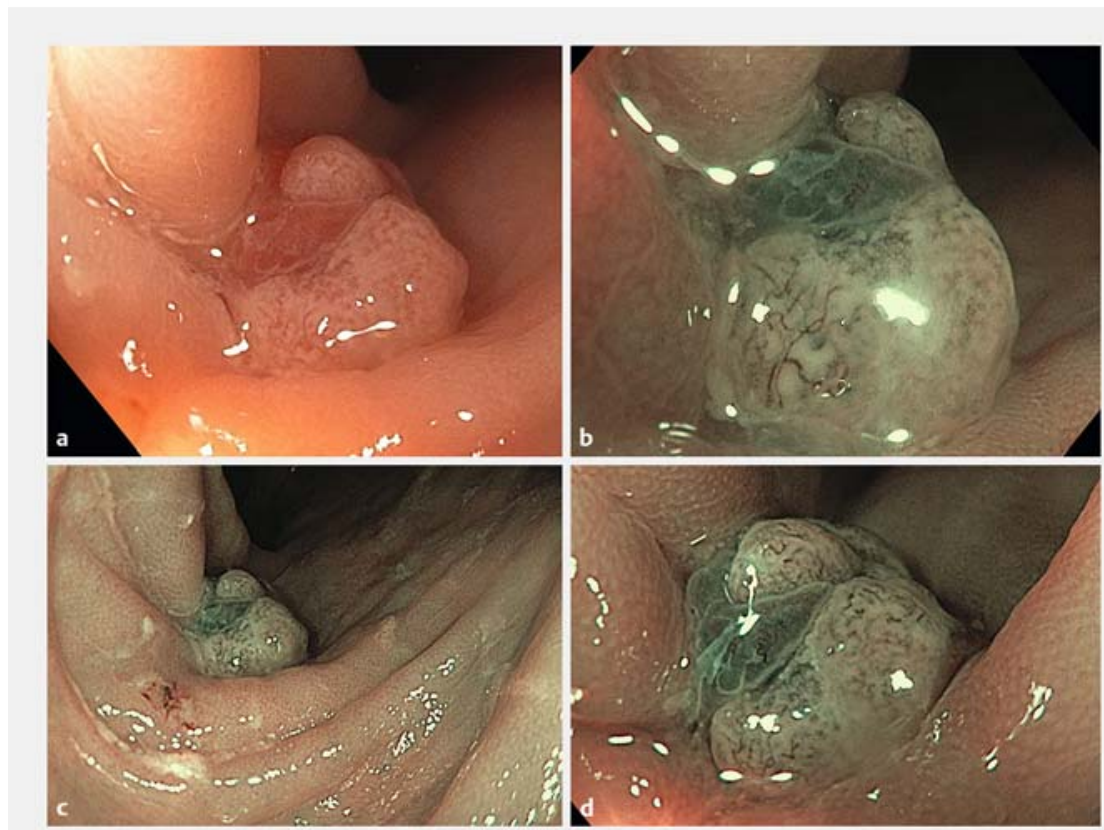

- Fig. 1 Polypoid lesion in the sigmoid colon seen in: a white light; b a narrow-band imaging (NBI) view showing an amorphous mucosal pattern and large irregular vessels but without a demarcation line; $\mathbf{c}$ distant view; $\mathbf{d}$ closer view with NBI.

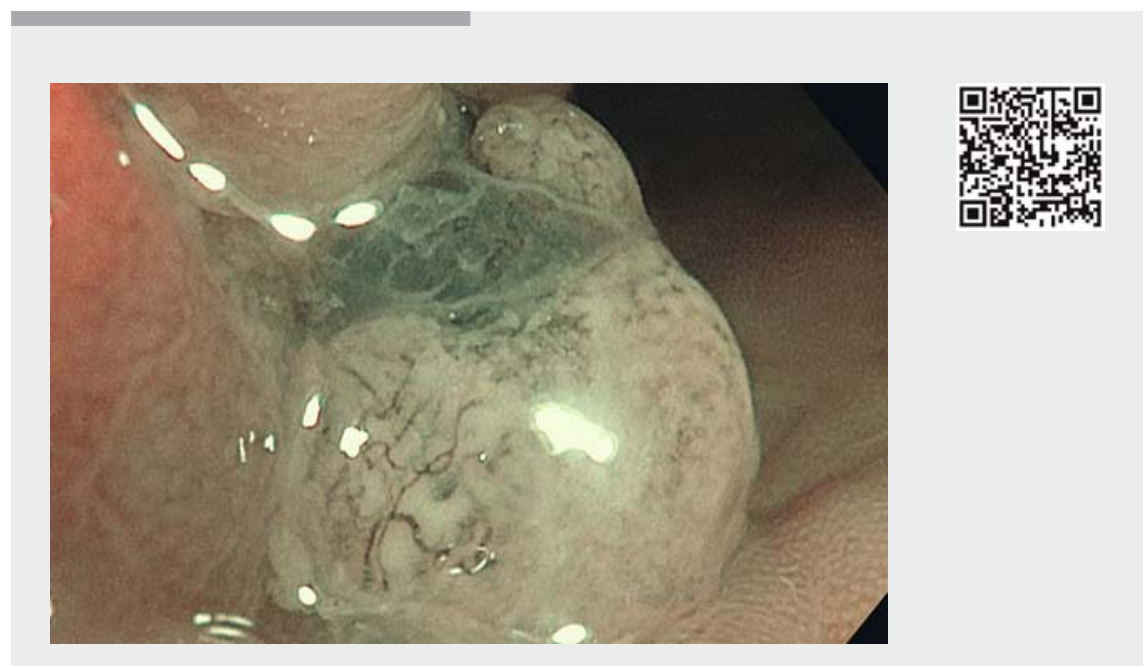

$\checkmark$ Video 1 Endoscopic appearances of two post-diverticulitis granular lesions with amorphous pit pattern and irregular vascular pattern. 

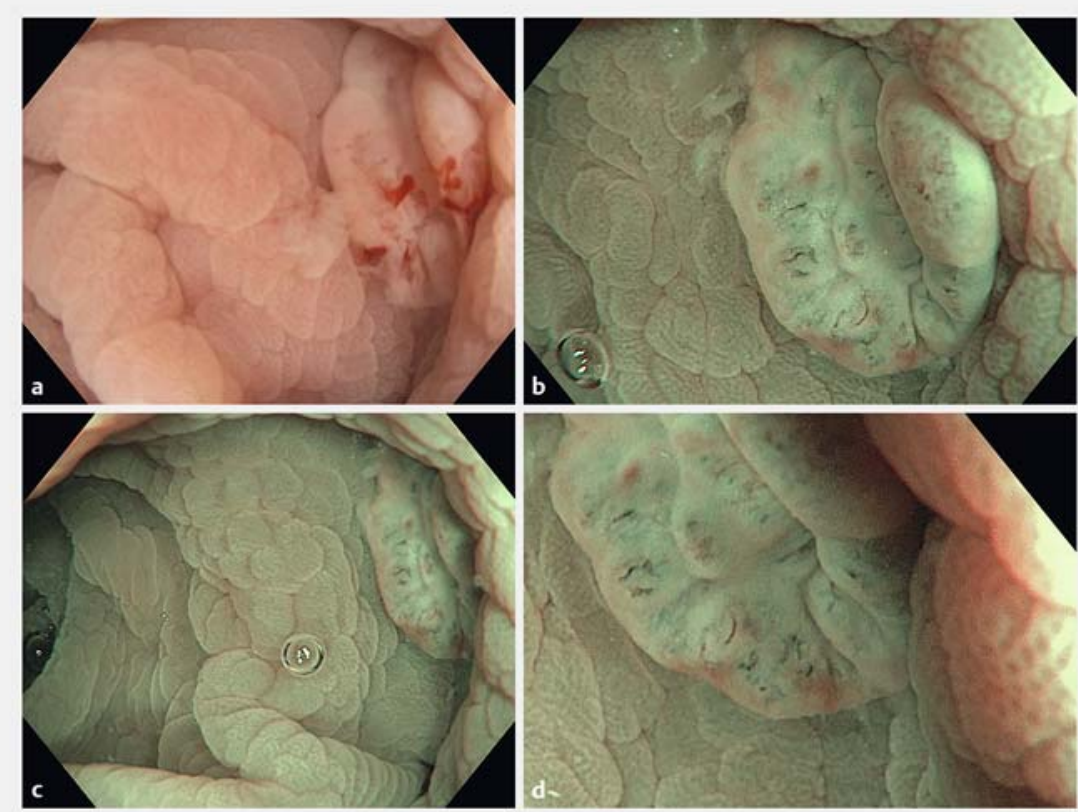

- Fig. 2 Pseudo-depressed lesion in the sigmoid colon seen in: a white light; $\mathbf{b}$ a narrow-band imaging (NBI) view showing an amorphous mucosal pattern and large irregular vessels but without a demarcation line; $\mathbf{c}$ distant view; $\mathbf{d}$ closer view with NBI.

\section{References}

[1] Kudo S, Rubio CA, Teixeira CR et al. Pit pattern in colorectal neoplasia: endoscopic magnifying view. Endoscopy 2001; 33: $367-373$

[2] Uraoka T, Saito Y, Ikematsu H et al. Sano's capillary pattern classification for narrowband imaging of early colorectal lesions. Dig Endosc 2011; 23 (Suppl. 01): 112-115

[3] Hayashi N, Tanaka S, Hewett DG et al. Endoscopic prediction of deep submucosal invasive carcinoma: validation of the narrowband imaging international colorectal endoscopic (NICE) classification. Gastrointest Endosc 2013; 78: 625-632

[4] Yamada M, Saito Y, Sakamoto T et al. Endoscopic predictors of deep submucosal invasion in colorectal laterally spreading tumors. Endoscopy 2016; 48: 456-464

\section{Bibliography}

DOI https://doi.org/10.1055/s-0043-109427

Endoscopy 2017; 49: E184-E185

(c) Georg Thieme Verlag KG

Stuttgart · New York

ISSN 0013-726X

\section{ENDOSCOPY E-VIDEOS}

https://eref.thieme.de/e-videos

Rivory ${ }^{1}$, Martin Fabritius ${ }^{1}$, Jean-Christophe Saurin ${ }^{1}$, Thierry Ponchon ${ }^{1,2}$, Mathieu Pioche ${ }^{1}$, 2

1 Department of Endoscopy and Gastroenterology, Pavillon L, Edouard Herriot Hospital, Lyon, France

2 Inserm U1032 LabTau, Lyon, France

\section{Corresponding author}

\author{
Mathieu Pioche, MD \\ Endoscopy unit - Digestive Disease \\ department, Pavillon L - Edouard Herriot \\ Hospital, 69437 Lyon, France \\ mathieu.pioche@chu-lyon.fr
}

